\title{
МОДЕЛИ ИНФОРМАЦИОННЫХ ПРОЦЕССОВ УПРАВЛЕНИЯ ИСПЫТАНИЯМИ В КОНСТРУКТОРСКОМ БЮРО
}

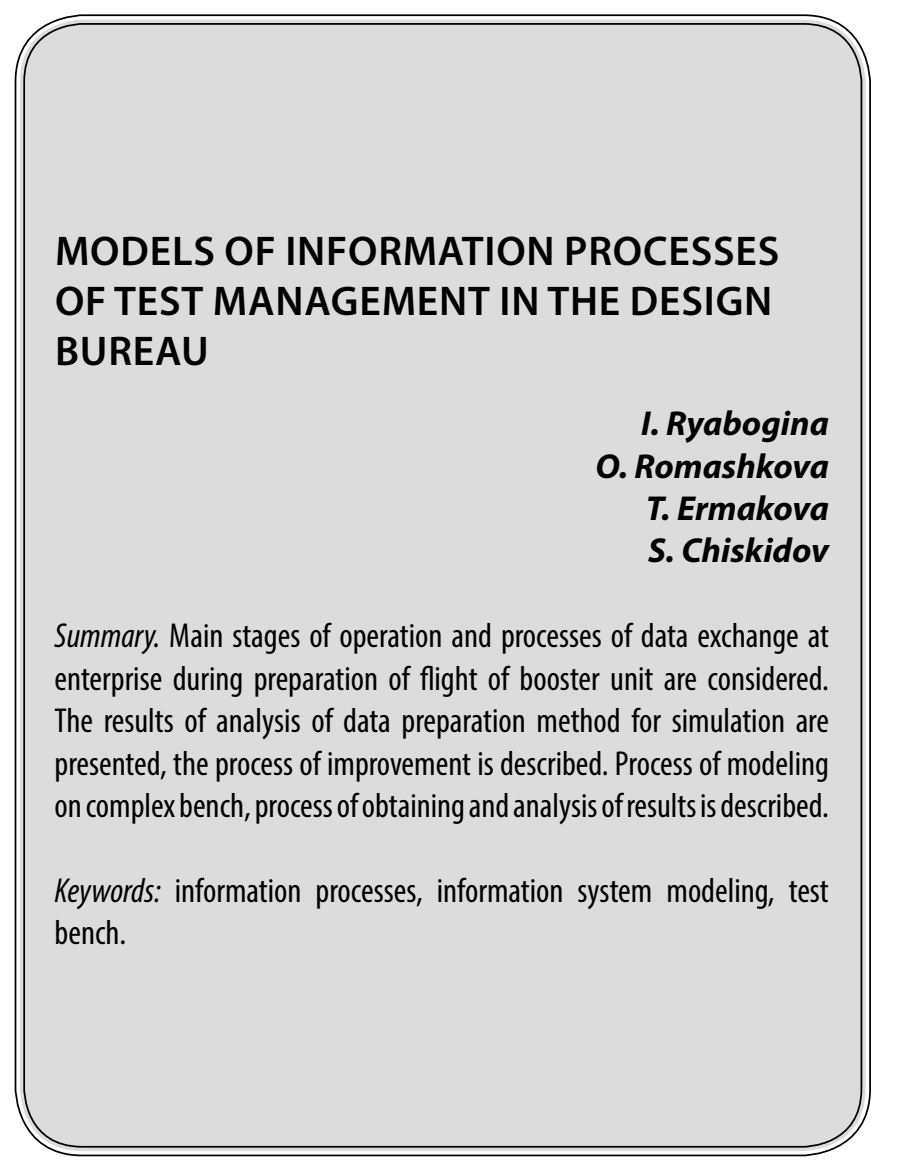

\section{Введение}

B ыведение космических аппаратов (КА) на орбиту может осуществляться как прямым способом за счет последовательного срабатывания ступеней ракеты-носителя (РН), так и с использованием дополнительной ступени - разгонного блока (РБ), в общем случае позволяющего реализовывать сложные схемы выведения, которые включают чередование активных и пассивных (баллистических) участков полета, оптимизирующих энергозатраты на выведение КА.

Прямой способ выведения характерен для построения орбит КА с малой высотой полета, а также эллиптических орбит. Простейшим РБ является так называемая апогейная ступень, одноразово срабатывающая в апогее переходной орбиты, сформированной $\mathrm{PH}$.

Существующая проблема автоматизации процессов, связанных с подготовкой к полету РБ и выводу космиче-
Рябогина Ирина Александровна

Аспирант, ГАОУ ВО «Московский городской педагогический университет (МГПУ)», г. Москва

iren89@bk.ru

Ромашкова Оксана Николаевна

Д.т.н., профессор, Российская академия народного хозяйства и государственной службы при Президенте

РФ (РАНХИГC)», г. Москва

ox-rom@yandex.ru

Ермакова Татьяна Николаевна

К.т.н., дочент, ГАОУ ВО «Московский городской педагогический университет (МГПУ)», г. Москва

ermaktat@bk.ru

чискидов Сергей Васильевич

К.т.н., доцент, ФГБВОУ ВО «Академия гражданской защиты МЧС России», г. Химки (Московская обл.) chis69@mail.ru

Аннотация. Рассмотрены основные этапы работы и процессы обмена данными на предприятии при подготовке полета разгонного блока. Представлены результаты анализа методики подготовки данных для моделирования, описан процесс усовершенствования данной методики. Описан процесс моделирования на комплексном стенде, процесс получения и анализа результатов.

Ключевые слова: информационные процессы, моделирование информационной системы, испытательный стенд.

ского летательного аппарата на целевую орбиту, осложнена следующими факторами:

- большим количеством исходных параметров, заданных в полетном задании (ПЗ);

- многоуровневым моделированием каждого полета на математических и полунатурных стендах;

- большим количеством оборудования, которое необходимо проверить и для проверки которого необходимо смоделировать соответствующие исходные данные;

- многочисленными параметрами телеметрии со стендов моделирования, которые нужно анализировать для выявления ошибок в расчетах на этапе подготовки к пуску;

- большим объемом документации, необходимой для отчетности по каждому конкретному пуску [1].

В процессе подготовки РБ к пуску участвуют несколько отделов, каждый из которых выполняет свои функци- 


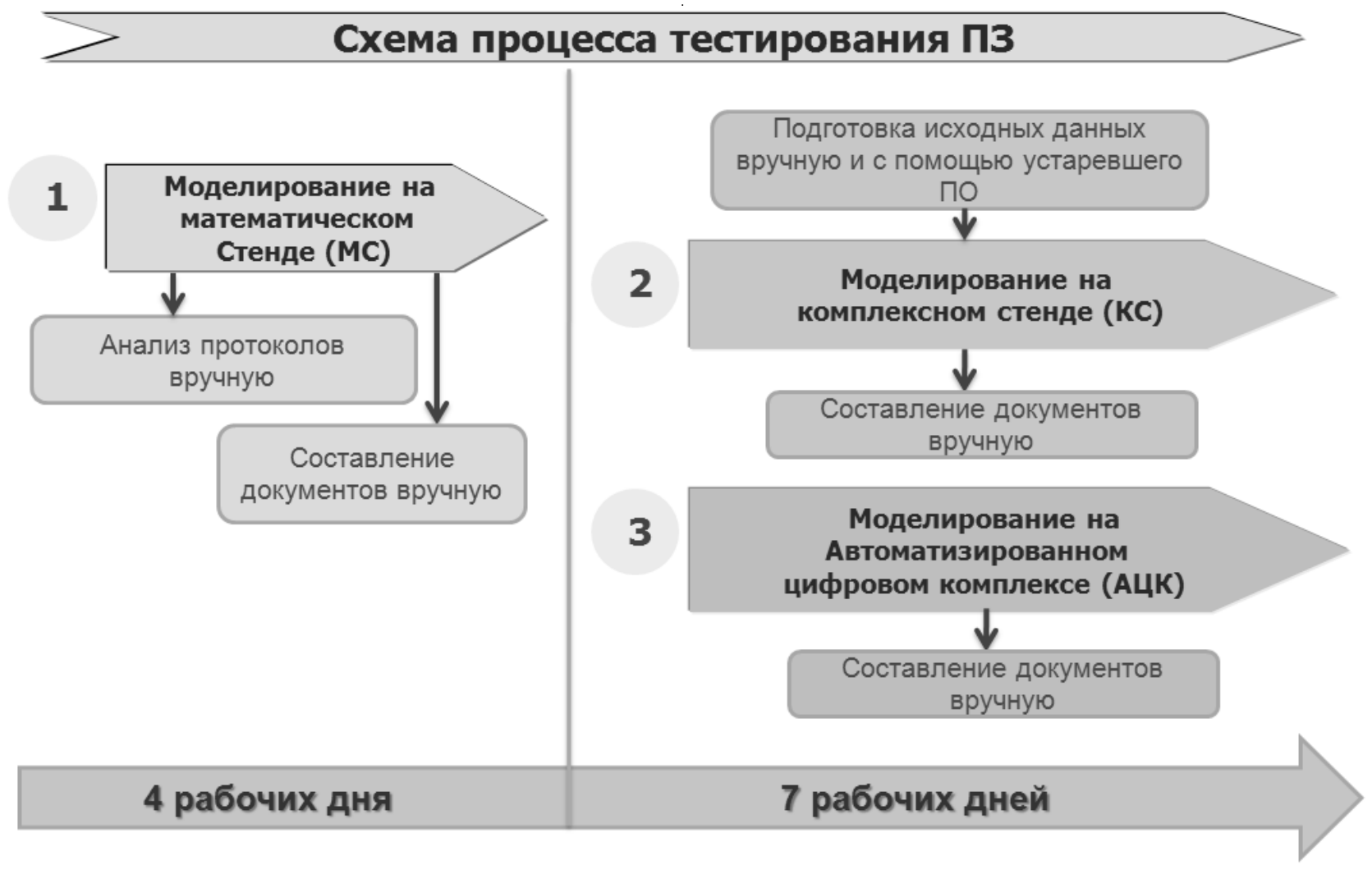

Рис. 1. Схема тестирования ПЗ на различных стендах

ональные задачи. По результатам проделанной работы формируются соответствующие документы, подтверждающие готовность аппарата и РБ к пуску [2].

Многие процессы подготовки, моделирования и анализа уже автоматизированы. Некоторое программное обеспечение (ПО) требует доработки, некоторое - полной замены, а большая часть работы производится вручную. Поэтому целесообразно автоматизировать процесс подготовки и анализа исходных данных на всех этапах работы, а также рассмотреть возможность создания единой информационной системы (ИС) с базой данных для хранения, распространения и обработки информации и документации.

Для разработки специализированной ИС необходимо выполнить все этапы проектирования, а также оценить возможность автоматизации формирования базы исходных данных для ИС.

Проблеме автоматизации процессов управления, связанных с подготовкой к полету разгонного блока, посвящена данная работа.

Основные этапы испытаний разгонного блока в конструкторском бюро
Рассмотрим основные этапы испытаний и процессы управления обменом данных на предприятии при подготовке полета разгонного блока.

В формировании П3, которое содержит в себе основные данные для реализации выведения КА на целевую орбиту, участвуют несколько предприятий, каждое из которых отвечает за свой раздел.

После составления полетного задания для конкретного пуска, начинается подготовка исходных данных для моделирования полета на различных стендах [3].

Комплексная отработка и испытания на моделирующих стендах производятся с целью:

1. Выявления возможных ошибок, внесенных в бортовое ПО или ПЗ в процессе их формирования;

2. Аттестации работоспособности и качества работы бортового ПО и ПЗ в различных условиях полета;

3. Проведения оценок точности построения целевой орбиты и величин расхода топлива в ходе выполнения циклограммы выведения [4].

На рисунке 1 представлена схема тестирования ПЗ на различных стендах, выходные данные и их обработка без учета разработанного ПО. 


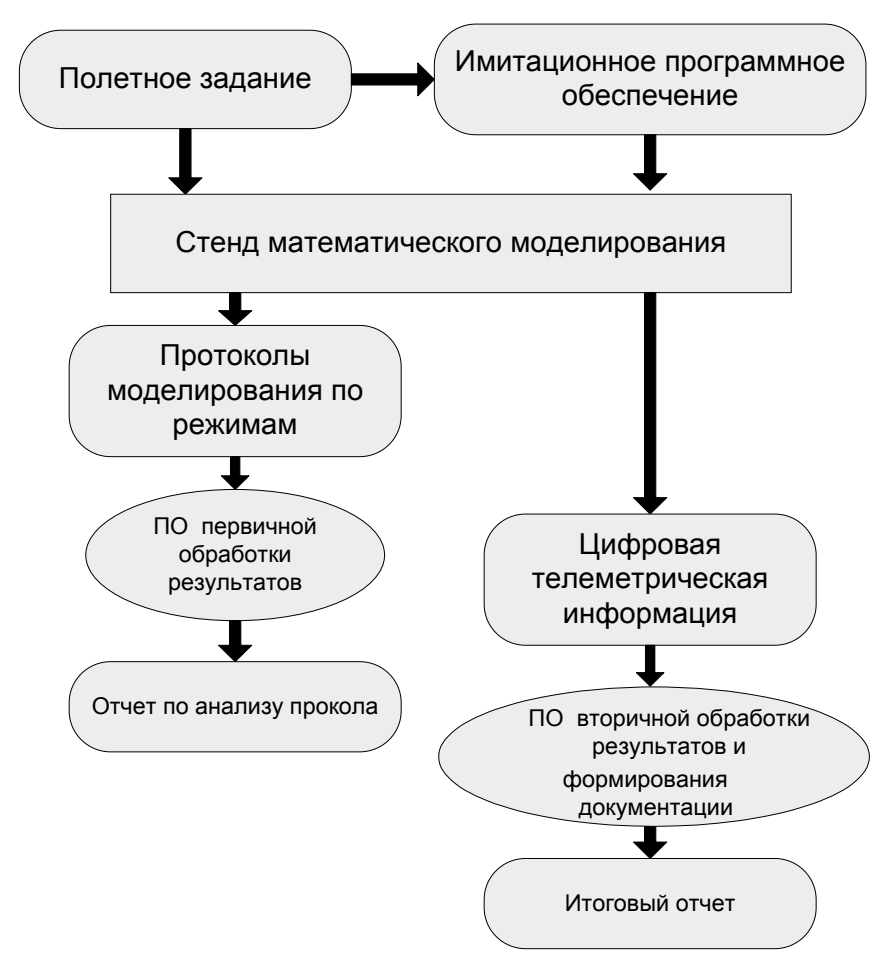

Рис. 2. Схема потоков данных при моделировании информационных процессов на математическом стенде
Стенды можно разделить на следующие группы:

1. Стенды математического моделирования (рисунок 2) на базе персональных ЭВМ, с помощью которых производятся испытания бортового ПО системы управления (СУ) в замкнутом контуре с имитацией внешней среды в ускоренном масштабе времени;

2. Стенды полунатурного моделирования на базе реальной бортовой цифровой вычислительной системы и персональных ЭВМ, с помощью которых производятся испытания бортового ПО с реальным бортовым вычислителем в замкнутом контуре с имитацией внешней среды в реальном масштабе времени (рисунок 3);

3. Комплексные стенды (рисунок 4), на которых производятся испытания аппаратуры и ПО СУ в незамкнутом контуре в реальном масштабе времени;

4. Стенд X (рисунок 5), на котором производятся испытания с реальным РБ [5].

\section{Комплексный \\ стен $\triangle$}

Для проведения испытаний на комплексном стенде необходимы следующие входные данные:

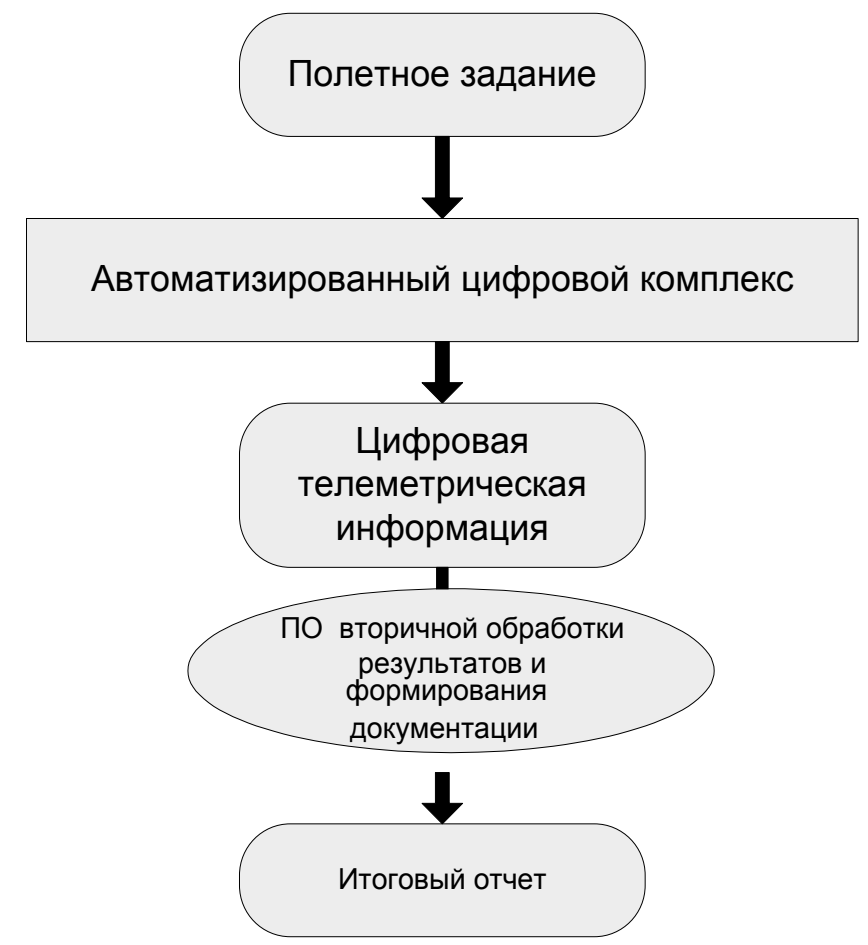

Рис. 3. Схема потоков данных при моделировании информационных процессов в автоматизированном цифровом комплексе

1. Версия ПО, которая формируется из ПЗ и файла данных имитации полета (ФДИП);

2. Файл настройки имитации полета (ФНИП).

На комплексных стендах моделирование полета происходит в реальном времени, в течение двадцати часов. Поэтому для проверки ПЗ, ФДИПа и ФНИПа была разработана программа сокращенного полета, которая проверяет соответствие времен выдачи команд различных процессов, содержащихся в соответствующих файлах. Также для ускорения процесса разработано ПО автоматического формирования ФДИП и ФНИП по данным из разделов ПЗ [6].

\section{Формирование файла Аанных имиташии полета}

ФДИП формируется по данным ПЗ и представляет собой последовательность команд, которая выдается на бортовую СУ, как реакция на достижение того или иного состояния РБ в полете.

Методика формирования файла заключалась в том, что последовательно, исходя из логики полета, производился расчет времени и команда, выдаваемая в это время, записывалась в файл [7]. 


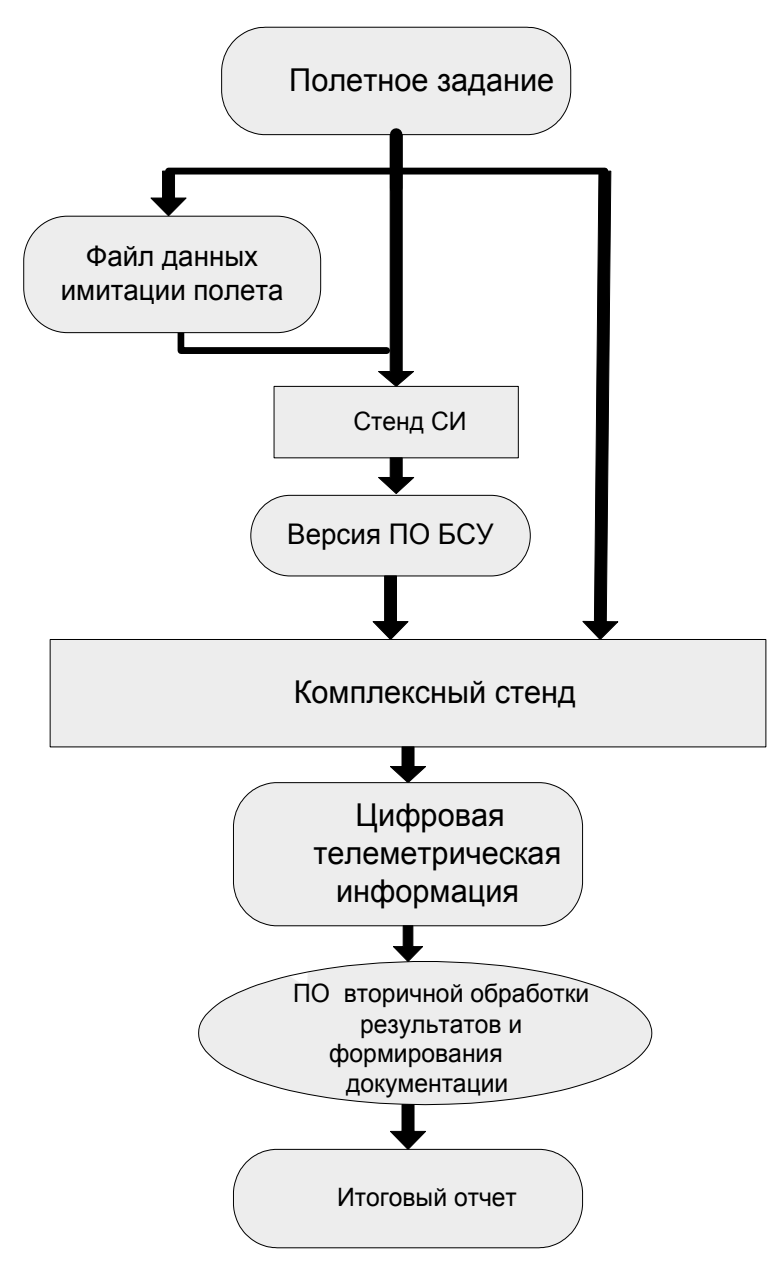

Рис. 4. Схема потоков данных при моделировании на комплексном стенде

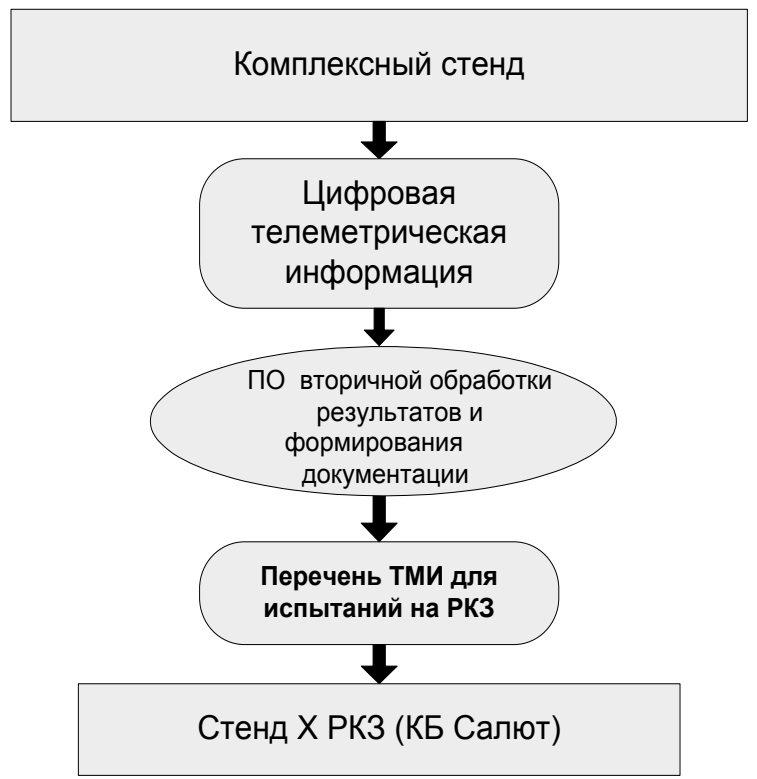

Рис. 5. Схема потоков данных при моделировании на Стенде X РКЗ
ПО для формирования ФДИП было написано на языке Fortran и представляло собой несколько программных модулей, работающих независимо друг от друга, и подключаемых в определенный момент времени. В начале работы программы запускался счетчик тактов, и в нужный момент генерировались соответствующие команды. После анализа ФДИП, сформированных старым ПО, можно было определить, что последовательность изменения по времени значений команд имеет определенную закономерность. Для каждого отдельного фрагмента файла можно определить время начала, время окончания и точную последовательность изменения команд. В результате, было разработано новое ПО с другим принципом формирования данных.

\section{Новая методика \\ формирования ФАИП}

После анализа структуры файла можно разделить ФДИП на несколько составных частей, повторяющихся в зависимости от данных из ПЗ.
Можно выделить две основные составляющие части полета - это активные (рисунок 6) и пассивные (рисунок 7) участки. Частные циклограммы и их реализации принципиально отличаются друг от друга.

Активные участки включают в себя следующие частные циклограммы:

1. Циклограмму включения маршевого двигателя (МД) - в данной циклограмме отражены моменты начала поджатия топлива в топливных баках, выдачи временных меток, обозначающих начало активного участка и включения МД. Значения соответствующих моментов времени заданы в ПЗ.

2. Циклограмму № 1, которая является имитацией управления рулевыми приводами МД на активных участках и включает в себя формирование сигналов отклонения приводов по тангажу и рысканию. Циклограмма № 1 задействуется через 5 секунд после формирования команды на включение маршевого двигателя. Причем на четных маневрах последовательность формирования 


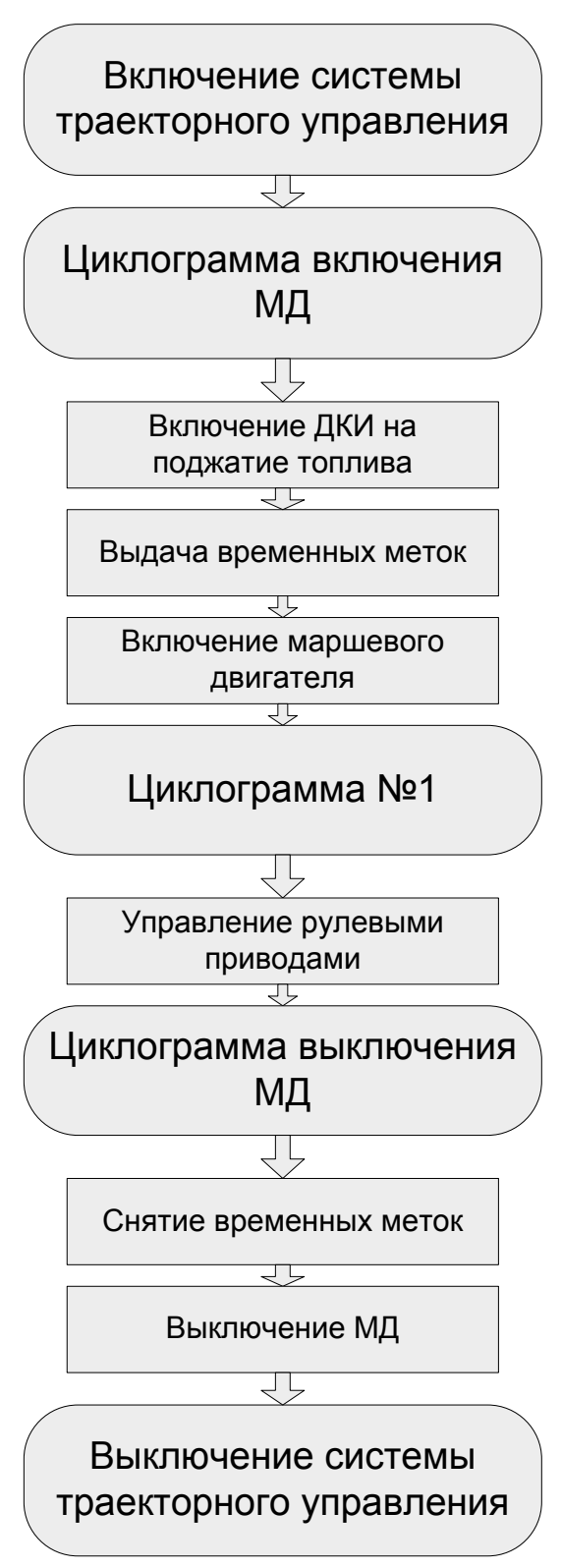

Рис. 6. Структура любого активного участка полета

сигналов по каналам управления меняется местами.

3. Циклограмму выключения МД - в ней отражены моменты выдачи временных меток окончания активного участка и выключения МД [8].

Пассивные участки включают в себя следующие частные циклограммы:

1. Циклограмму № 2, которая используется на пассивном участке и имитирует стабилизацию по трем каналам при различных вариантах включения двигателей малой тяги (ДМТ). Эта циклограмма задействуется через 460 тактов после

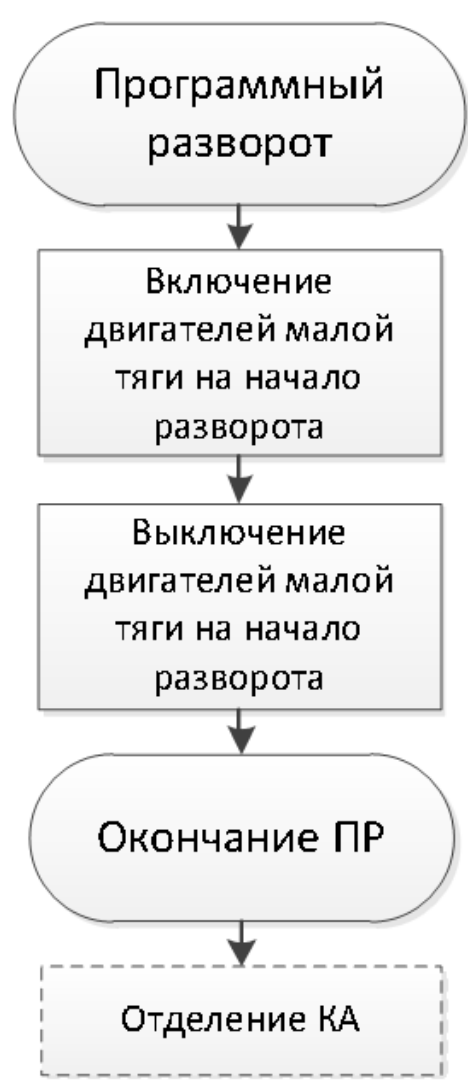

Рис. 7. Структура любого пассивного участка окончания первого маневра и после сброса дополнительного топливного бака (ДТБ).

2. Циклограмму № 3, которая используется для контроля отработки ДМТ на пассивном участке управляющих сигналов типа «гребенка» и подключается один раз после первого завершения циклограммы № 2.

3. Циклограмму отделения (ДТБ) - в данном алгоритме выдаются следующие команды: предварительная команда для отделения ДТБ, признак готовности к отделению ДТБ, признак расстыковки электросоединителей. Времена формирования команд заданы в ПЗ. 
4. Циклограммы № 4, № 5, № 6 - отражают этапы выполнения типовых программ разворота на пассивных участках полета и подключаются в следующие моменты:

- циклограмма № 4 - в момент начала типовой программы разворота, заданного по П3;

- циклограмма № 5 - в момент завершения разворота, заданный по П3;

- циклограмма № 6 - в момент достижения конца типовой программы разворота.

При длительности сохранения постоянного уровня сигналов управления рулевым приводом и неизменности команд включения/выключения ДМТ на уровне 150 тактов продолжительность циклограмм 1, 2, 3 равна соответственно 85 с, 95 с, 30 с, а циклограмм 4, 5, 6 по 5 секунд.

Если этапы типовых программ разворота, определяемые циклограммами 4, 5, 6, находятся в пределах выполнения циклограмм 2, 3, приоритет имеют циклограммы 2, 3 и соответствующие циклограммы не используются.

Если циклограмма 5 попадает в область циклограммы 6, то циклограмма 5 не используется.

Если циклограммы 5, 6 попадают в область блокировки управления двигателями малой тяги (например, накладываются на момент формирования команд на отделение КА), то циклограммы 5, 6 не используются.

5. Циклограмму отделения КА.

Отделение КА может осуществляться либо непосредственно после последнего выключения МД (в ориентации, полученной на момент выключения МД), либо после выполнения разворотов, обеспечивающих приведение РБ в заданную ориентацию, а также закрутку КА. Все характеристики операции отделения КА задаются в ПЗ [9].

Алгоритмы могут повторяться в зависимости от состава типовых полетных операций (ТПО), заданных в ПЗ.

Новая методика формирования ФДИП ориентирована на активные и пассивные участки в отдельности. Сначала работа по расчету времен производится только для активных участков, и записываются соответствующие данные, затем производится расчет времен выдачи команд на пассивных участках. Имея все необходимые данные неструктурированного вида, используя метод сортировки (по времени), мы получаем готовый файл, который содержит всю необходимую информацию и удовлетворяет логике полета.

\section{Фай^ настройки имиташии полета}

ФНИП предназначен для обеспечения комплексных испытаний, имитирует команды смежных систем через ИСС-4, проводит контроль выполнения событий имитации полета.

Формирование ФНИП производилось вручную по данным ПЗ и ФДИП. Рассчитывались времена выдачи соответствующих команд. Особенность файла настройки заключается в том, что в нем фиксируются только нужные для имитации на комплексном стенде события. Время рассчитывается как среднее арифметическое между предыдущим и последующим событием. Таким образом, файл настройки определяет временной промежуток, в который должны быть зафиксированы изменения на аппаратуре комплексного стенда. Помимо времен и названий ТПО, файл настройки также содержит маски, которые определяют, какие слова, содержащиеся в кадре бортовой цифровой вычислительной системы, проверяются в данный момент.

\section{Метолика}

формирования ФНИП заключалась в том, что сотрудники вручную с помощью калькулятора вычисляли по данным ПЗ и временам, взятым из файла данных имитации полета, временные промежутки, в которые происходят события, и по кадрам выставляли маски. Новое ПО разработано на основе методики формирования ФДИП с отличием в числе участков полета, которые необходимо отразить в файле и в принципе расчета времени.

\section{Зак^ючение}

Авторами рассмотрены главные стадии деятельности и процессы обмена данными в организации в процессе подготовки полета разгонного блока. Получена оценка методики подготовки данных для моделирования и дана характеристика процесса модернизации существующей методики. Дано описание информационных процессов моделирования, получения и анализа результатов на комплексном стенде.

\section{ЛИТЕРАТУРА}

1. Горелов Г.В., Ромашкова 0.Н., Чан Т.А. Качество управления речевым трафиком в телекоммуникационных сетях // Москва, Радио и связь. 2001.

2. Ермакова Т.Н., Ромашкова 0.Н., Пономарева Л.А. Модернизированная структура управления образовательной системой // Вестник Брянского государственного технического университета. 2019. № 6 (79). С. 84-91. 
3. Кондратьева Л.А., Ромашкова 0.Н. Системы регулирования движения на железнодорожном транспорте: Учебник для техникумов и колледжей ж.-д. транспорта. М.: Маршрут, 2003. - 52 c.

4. Gaidamaka Y.V., Romashkova 0.N., Ponomareva L.A., Vasilyuk I.P. Application of information technology for the analysis of the rating of university // B c6opнике: CEUR Workshop Proceedings 8. Cep. "ITTMM 2018 — Proceedings of the Selected Papers of the 8th International Conference "Information and Telecommunication Technologies and Mathematical Modeling of High-Tech Systems'"'. 2018. C. 46-53.

5. Romashkova 0.N., Ponomareva L.A., Chiskidov S.V. Instrumental implementation of the educational process model to improve the rating of the universities // CEUR Workshop Proceedings 8. Cep. "ITTMM 2019 - Proceedings of the Selected Papers of the 8th International Conference "Information and Telecommunication Technologies and Mathematical Modeling of High-Tech Systems'"' 2019. C. 92-101.

6. Ромашкова 0.Н., Ермакова Т.Н. Повышение эффективности управления информационными потоками в образовательном комплексе // Вестник Рязанского государственного радиотехнического университета. 2016. № 57. С. 82-87.

7. Romashkova 0.N., Belyakova A.V., Ponomareva L.A. Information model of data management in network online educational systems // В cборнике: Proceedings of the 2021 IEEE Conference of Russian Young Researchers in Electrical and Electronic Engineering, ElConRus 2021. 2021. C. 2226-2229.

8. Ромашкова 0.Н., Фролов П.А. Технология расчета показателей прибыли и рентабельности в коммерческой организации // Фундаментальные исследования. 2016. № 4-1. С. 102-106.

9. Romashkova 0.N., Lomovtsev R.S., Ponomareva L.A. Automation of data storage structures intelligent generation about the activities of educational organizations // В сборнике: Proceedings of the 2021 IEEE Conference of Russian Young Researchers in Electrical and Electronic Engineering, ElConRus 2021. 2021. C. 2230-2234.

( Рябогина Ирина Александровна ( iren89@bk.ru ), Ромашкова Оксана Николаевна ( ox-rom@yandex.ru ),

Ермакова Татьяна Николаевна ( ermaktat@bk.ru), Чискидов Сергей Васильевич ( chis69@mail.ru ).

Журнал «Современная наука: актуальные проблемы теории и практики»

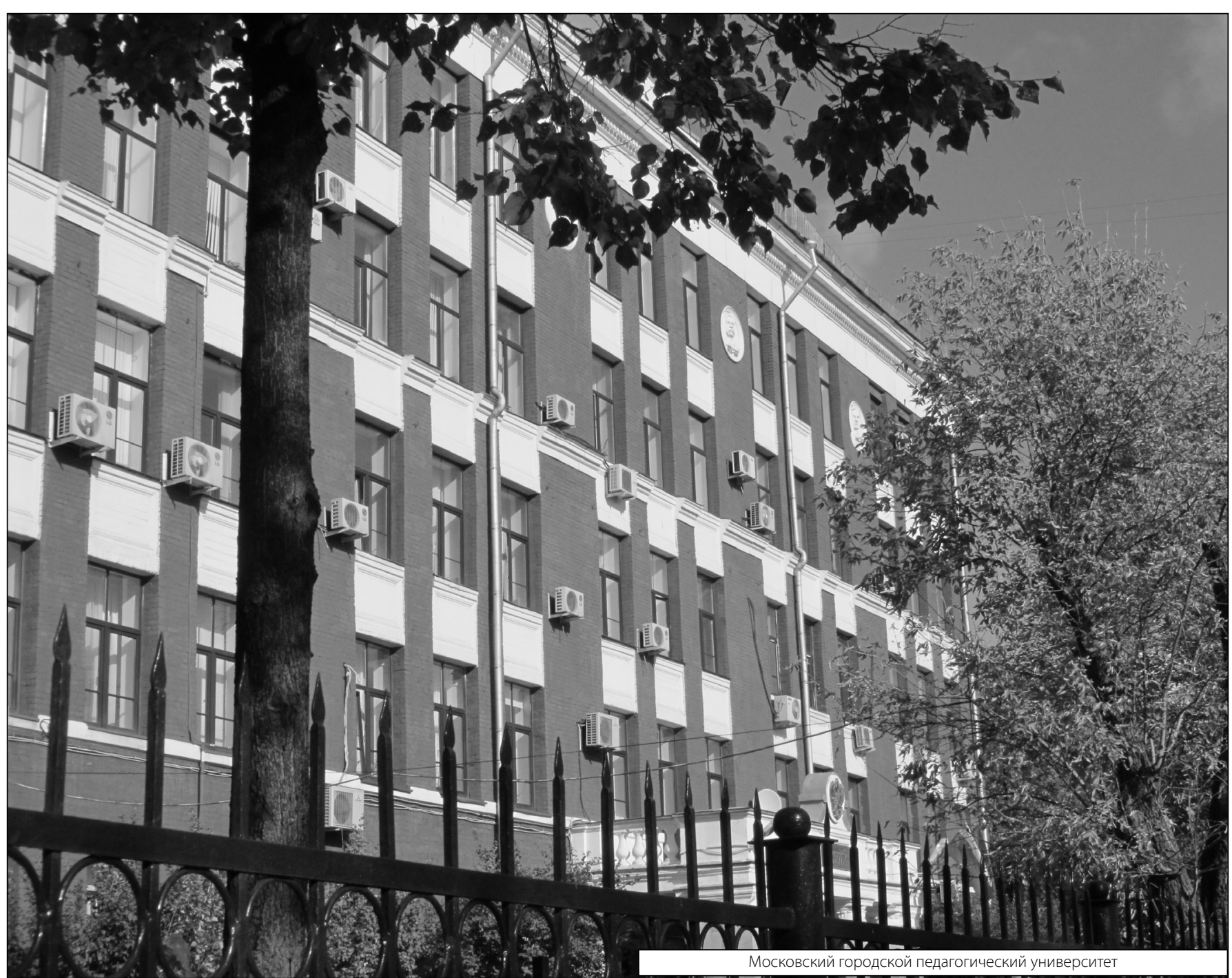

